\title{
Correction of nostril show
}

\author{
Sung II Cho, MD, PhD $\mathbb{D}$, Jeonghyun Oh, MD, PhD $\mathbb{D}$, Ji Yun Choi, MD, PhD $\mathbb{D}$ \\ Department of Otolaryngology-Head and Neck Surgery, Chosun University College of Medicine, Gwangju, Rep. of Korea
}

\begin{abstract}
A majority of alar rim deformity cases arises from the procedural complications of rhinoplasty. However, an increasing interest in the aesthetic aspects of alar rim deformity has led patients with congenitally retracted or hanging alae to seek revision surgeries. Alar retraction is predominantly caused by an excessive cephalic orientation or overmedialization of the lower lateral cartilage and a lack of soft tissue around the alar rim. The aim of this article is to present the case of a 59-year-old female patient with retracted alae from cephalically malpositioned lower lateral cartilages. We addressed these by using an external rhinoplasty approach to separate lower lateral cartilage from the surrounding tissues and apply an alar spreader graft and intergrated lateral crural strut graft to effectively correct the nostril show without any significant adverse effects.
\end{abstract}

Keywords: correction; nostril; retraction; rhinoplasty

\section{Introduction}

Because alar rim deformity is one of the most common abnormalities observed following rhinoplasty, extensive interest in the aesthetic appearance of the alar rim has promoted a growing trend among patients with congenital alar defects, such as retracted or hanging alae, to seek medical attention. Because of the level of technical difficulty required and the challenge in predicting the surgical outcome of an alar correction, it is rather important to assess the intraoperative variables of the cause, condition and degree of deformation in selecting an appropriate method prior to surgery [1].

Gunter et al. [2] evaluated the relationship between the columella and the alar margin to define the ideal alar-columellar proportion as being 1-2 $\mathrm{mm}$ from the long axis of the nostril to either the alar rim or the columella. Hence, an alar retraction would be typically characterized as the distance between the long axis of the nostril and the lower border of the ala being greater than $2 \mathrm{~mm}$. Alar retraction is one of the most commonly observed types of alar deformity, which can present considerable technical difficulty because of its high recurrence rate. This can frequently be observed in patients who have not undergone surgery, although it is predominantly caused by complications of rhinoplasty. Apart from its anomalous aesthetic nature, an alar retraction is often accompanied by functional disorders, such as the narrowing of the external valve. In addition, it holds the cultural importance of being regarded as unfavorable, according to the Asian interpretations of facial reading $[1,2]$. The most common complications associated with alar retraction are excessive cephalic orientation or overmedialization of the lower lateral cartilage (LLC) and the lack of soft tissues around the alar rim [3]. Normally, the lateral crura follow the curvature of the alar margin before diverging at a $30^{\circ}$ to $45^{\circ}$ angle toward the lateral canthus at the mid ala. A more cephalic orientation means that the lateral crus instead is directed in a more vertical orientation (cephalic referring to the top of the head) as it leaves the midline of the nose. If you measure the angulation of the lateral crura as they diverge off of midline, any angle less than

Received October 21, 2020; Revised November 23, 2020; Accepted November 23, 2020

Corresponding author: Ji Yun Choi

E-mail: happyent@naver.com

This is an Open Access article distributed under the terms of the Creative Commons Attribution Non-Commercial License (http://creativecommons.org/licenses/by-nc/4.0), which permits unrestricted non-commercial use, distribution, and reproduction in any medium, provided the original work is properly cited.

Copyright $@ 2021$ Korean Society of Korean Cosmetic Surgery and Medicine (KSKCS \& KCCS). 
$30^{\circ}$ can be considered cephalically positioned [4]. In an earlier study, Constantian found that cephalic malposition of the alar cartilage occurred at lower rates, with $18 \%$ of primary rhinoplasty patients and up to $42 \%$ of secondary rhinoplasty patients being affected [5].

\section{Case report}

A 59-year-old female patient visited the clinic with concerns about nostril show. The patient presented with no history of trauma or surgery (Fig. 1). Physical examination indicated a wide and low profile of the dorsum, narrow nasal tip, alar retraction, and nostril asymmetry. No significant endoscopic findings

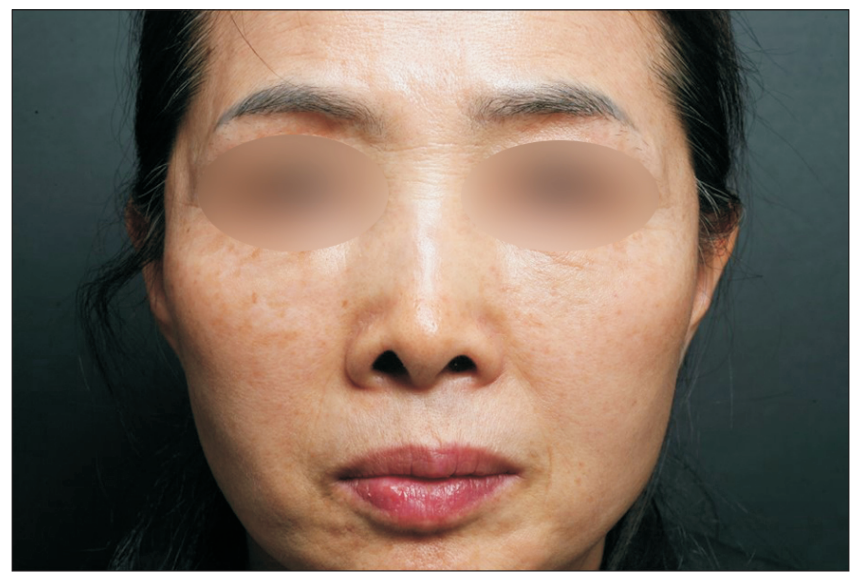

Fig. 1. Preoperative photo of frontal view shows severe nostril show, alar asymmetry and weak nasal tip.
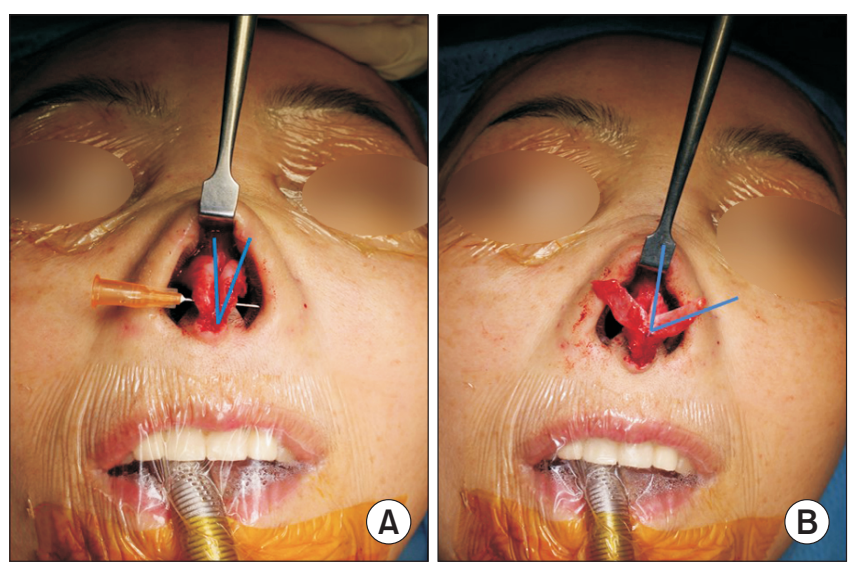

Fig. 2. (A) Intraoperative photo shows cephalically oriented lateral crus of lower lateral cartilage. (B) Intraoperative photo shows caudally repositioned lateral crus of lower lateral cartilage after released from upper lateral cartilage, underlying mucosa and pyriform ligament. were observed except for a slight septal deviation to the left

Under general anesthesia, local lidocaine $1 \%$ and epinephrine 1:100,000 were injected into both sides of the nasal cavity and septum, including the dorsum. After 15 minutes, an inverted V incision was performed using a \#11 and a \#15 scalpel blade to connect with the marginal incision. The cartilaginous and bony vault of the nose was exposed by undermining the skin from the dorsum area. Once the mucous membranes had been gently separated from the septum on both sides, the anterior portion of the septum and the entire nasal septum was fully exposed. Deviation of the septal cartilage to the left was observed. We harvested $2 \mathrm{~cm} \times 2 \mathrm{~cm}$ of septal cartilage from the posteroinferior margin of the nasal septum to correct the septal deviation. Besides the septal deviation, also the excessive cephalic orientation of the LLC was observed (Fig. 2). In order to bilaterally reposition of the LLC, it was freed from the upper lateral cartilage (ULC), the underlying mucosa of cartilage, and the pyriform ligament. Then we performed a septal extension graft using the septal cartilage for tip derotation. After the LLC had been caudally and laterally repositioned, an alar spreader graft was applied to the ULC and upper portion of septal cartilage. We tried to reposition of right LLC more caudally for the symmetry. Additionally, the alar rim was lowered by performing an intergrated lateral crural strut graft in an oblique orientation along the inferior border of the LLC (Fig. 3). The graft was inserted and fixed inside a subcutaneous pocket along the alar margin. We then corrected the wide nasal dorsum by performing a lateral osteotomy on both sides, and the tip projection was improved by performing an onlay graft using the septal cartilage

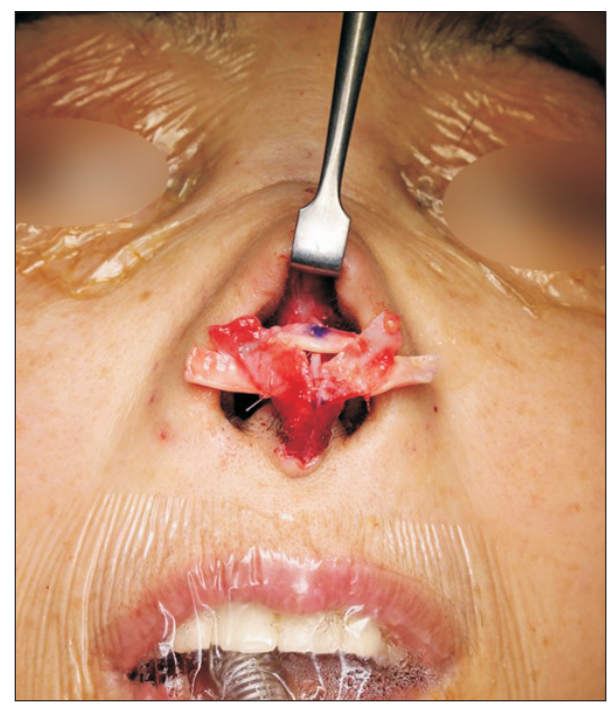

Fig. 3. Intraoperative photo shows alar spreader graft and integragted lateral crural strut graft. 

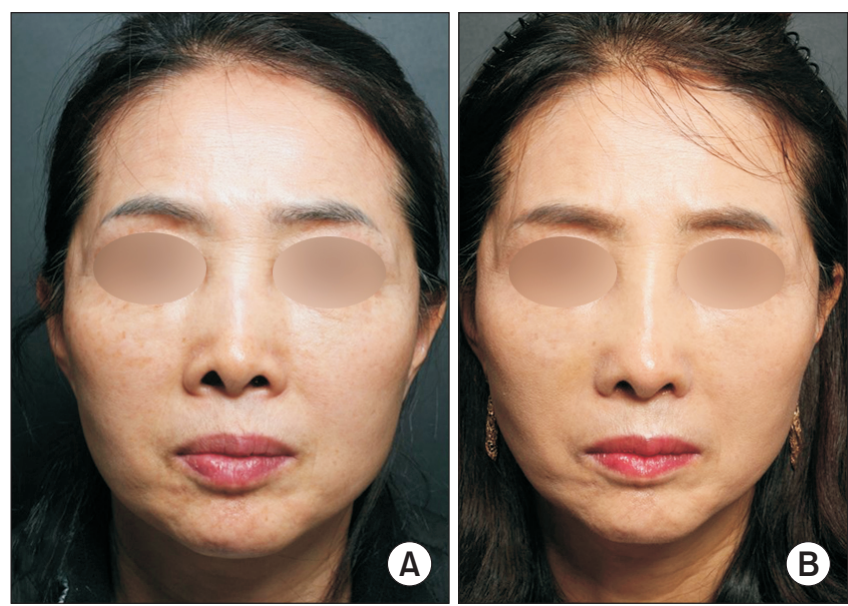

Fig. 4. Preoperative (A) and 1 year postoperative (B) photos of frontal view show improved nostril show.

over the the nasal tip. Subsequent to the alar base surgery, the incision was sutured using 5-0 nylon and 6-0 vicryl.

Following surgery, the patient presented with a highly functional and cosmetically satisfactory outcome as well as a significant improvement of the nostril show, without any adverse complications such as recurrence, infection, cartilage dislocation, or extrusion (Fig. 4). Note that this report has been accompanied by a review of the literature.

\section{Discussion}

Various surgical methods, including alar rim graft, lateral crural strut graft, auricular composite graft, intercartilaginous graft, alar extension graft, and V-Y advancement flap have been employed in the correction of alar retraction [6-13]. The surgical technique selected depends upon the degree of alar retraction, as well as other factors involving the condition of the surrounding skin and cartilaginous tissues. For mild revision cases, conservative procedures are usually preferred. Methods such as scar removal, alar rim graft, V-Y advancement flap, and auricular composite graft have been reported to be efficacious in the repair of mild-to-moderate nasal alar defects [6-13]. An alar rim graft, being the simplest technique, is indicated when the alar retraction is less than $2 \mathrm{~mm}$ with slight cartilage curvature. This can be performed during a primary or secondary rhinoplasty as a mean of preventing a potential retraction due to a weakened LLC [6]. Overmedialization of the LLC from scar contraction, excessive excision, or poor suturing is the primary cause of medial or central based alar notching. In such cases, an alar spreader graft or alar derotation graft is performed to reposition the LLC for the spreading of the cartilage, thus pro- ducing a natural looking appearance in the nasal wing $[14,15]$. During an alar spreader graft, the dorsal nasal flap is raised, and the LLC is freed from the ULC and pyriform ligament. Once the LLC is fully mobilized, it can be repositioned in an inferolateral direction, and the strut graft can be integrated between the central dorsum, above the ULC, and between the LLC. The LLC is secured laterally before suturing. Auricular or septal cartilage are suitable grafting materials. An alar spreader graft, which repairs the foundation of the ala by reorienting the nasal wing in the inferolateral direction. This type of graft is advantageous in correcting alar retraction caused by complications of retracted, upturned, or pinched nose from multiple revision surgeries [14]. An intergrated lateral crural strut graft is a modification of the conventional alar rim graft or alar contour graft that provides direct skeletal support to the entire crural-rim complex via a rigid integration into the tip framework. The intergrated lateral crural strut graft has proven to be a safe and effective alternative to the conventional alar rim graft. A graft of $20-25 \mathrm{~mm}$ by $4-5 \mathrm{~mm}$ dimension is placed along the LLC margin and secured medially to the tip and the lateral crus at three to four points before stabilizing the graft in subcutaneous pockets for anchoring the suture. As a result, the nasal wing is pulled down and alar rim stability fortified with cartilaginous support for the effective correction of alar retraction [16]. This clinical case was presented to address the use of an alar spreader graft and intergrated lateral crural strut graft to reposition the cephalically malpositioned LLC, providing an effective modality for treating alar retraction. Satisfactory results were obtained without complication noted during an 18-month follow-up, leading to our presentation of this case for literature review.

\section{Acknowledgments}

This study was supported by research fund from Chosun University Hospital 2018.

\section{Conflicts of interest}

The author have nothing to disclose.

\section{References}

1. Lee JE, Choi JY. Diagnosis and treatment of alar rim deformities. Korean J Otorhinolaryngol-Head Neck Surg 2016;59:9-14.

2. Gunter JP, Rohrich RJ, Friedman RM. Classification and correction of alar-columellar discrepancies in rhinoplasty. Plast 
Reconstr Surg 1996;97:643-8.

3. Jung DH, Kwak ES, Kim HS. Correction of severe alar retraction with use of a cutaneous alar rotation flap. Plast Reconstr Surg 2009;123:1088-95.

4. Toriumi DM. Nasal tip contouring: anatomic basis for management. Facial Plast Surg Aesthet Med 2020;22:10-24.

5. Constantian MB. The boxy nasal tip, the ball tip, and alar cartilage malposition: variations on a theme--a study in 200 consecutive primary and secondary rhinoplasty patients. Plast Reconstr Surg 2005;116:268-81.

6. Rohrich RJ, Raniere J Jr, Ha RY. The alar contour graft: correction and prevention of alar rim deformities in rhinoplasty. Plast Reconstr Surg 2002;109:2495-505; discussion 2506-8.

7. Guyuron B. Alar rim deformities. Plast Reconstr Surg 2001;107:856-63.

8. Tardy ME Jr, Toriumi D. Alar retraction: composite graft correction. Facial Plast Surg 1989;6:101-7.

9. Gunter JP, Friedman RM. Lateral crural strut graft: technique and clinical applications in rhinoplasty. Plast Reconstr Surg 1997;99:943-52; discussion 953-5.
10. Kim HS, Roh SG. The alar extension graft for retracted ala. J Korean Soc Plast Reconstr Surg 2009;36:66-74.

11. Gruber RP, Kryger G, Chang D. The intercartilaginous graft for actual and potential alar retraction. Plast Reconstr Surg 2008;121:288e-96e.

12. Kim DY, Kim IS, Jin HR. Frequently used grafts in Korean rhinoplasty: nomenclature and definitions. Korean J Otorhinolaryngol-Head Neck Surg 2010;53:412-8.

13. Choi JY, Javidnia H, Sykes JM. New techniques for correction of severe alar retraction using an island pedicled advancement flap of the nasal dorsum. J Plast Reconstr Aesthet Surg 2013;66:1803-4.

14. Kim JH, Park SW, Oh WS, Lee JH. New classification for correction of alar retraction using the alar spreader graft. Aesthetic Plast Surg 2012;36:832-41.

15. Paik MH, Chu LS. Correction of the short nose using derotation graft. Arch Aesthetic Plast Surg 2012;18:35-44.

16. Kao WTK, Davis RE. Postsurgical alar retraction: etiology and treatment. Facial Plast Surg Clin North Am 2019;27:491-504. 